\title{
INTRODUCTION : POURQUOI UN PROGRAMME SUR LA GÉNÉTIQUE DE LA TRUITE COMMUNE ?
}

\author{
B. Chevassus et E. VIGNeuX*
}

Laboratoire de Génétique des Poissons - INRA - 78350 JOUY-EN-JOSAS

* Conseil Supérieur de la Pêche - Domaine du Paraclet - BP 5 - 80440 BOVES

Dans l'esprit du grand public, le champ d'application de la génétique animale est essentiellement celui de l'amélioration génétique des animaux domestiques. En outre, les critères visés par les schémas d'amélioration génétique sont le plus souvent des critères de production (croissance, fertilité) ayant un impact important sur la rentabilité des élevages. C'est pourquoi on peut s'interroger sur l'intérêt de développer des études sur la génétique de la truite commune, espèce peu utilisée en pisciculture de production et représentée essentiellement par des populations vivant dans le milieu naturel.

Pourtant, le C.S.P. a, dès le début des années 80 , pris plusieurs initiatives importantes pour inciter I'INRA à réaliser des études sur la génétique de la truite commune: mise à disposition d'une trutticulture expérimentale (Gournay sur Aronde, Oise), aide financière dans le cadre de contrats pluriannuels de recherche sur ce thème, aide des fédérations et des agents de terrain du C.S.P. pour l'échantillonnage des populations naturelles.

Quel était donc l'objectif de ces études? On peut le résumer par une question : n'y avait-il pas contradiction entre une politique de gestion et de repeuplement considérant implicitement la truite commune comme une espèce homogène, et les observations empiriques, parfois étayées par des observations scientifiques précises, insistant sur l'originalité écologique ou géographique de certaines populations? En corollaire, la question des conséquences éventuelles de cette politique était bien sûr posée: peut-elle conduire à une inefficacité des repeuplements ou au contraire à une "pollution génétique" des populations naturelles, ce terme de "pollution" étant d'ailleurs à définir précisément.

Par rapport à cette question, la position initiale des généticiens était nuancée: habitués à ne pas attribuer à des effets génétiques toute variation "inexpliquée" entre des individus ou des populations sans une analyse approfondie, ils avaient tendance à relativiser les observations de terrain, notamment vis-à-vis des "formes écologiques" de l'espèce (truite de mer, truite de lac, truite sédentaire). D'autre part, les données disponibles sur des populations naturelles d'autres espèces conduisaient à penser que les populations de truite commune n'étaient certainement pas des "races pures" constituées d'individus génétiquement identiques mais sans doute formées des entités présentant une certaine variabilité interne. A contrario, on pouvait trouver chez des espèces végétales ou animales diverses des exemples illustrant la possibilité d'avoir des populations extrêmement semblables à l'observation externe, mais génétiquement très différenciées (espèces jumelles). On pouvait trouver également des exemples montrant les conséquences éventuellement néfastes du mélange de populations génétiquement très différenciées.

Les généticiens ont donc entamé un patient travail, à la fois d'observation et d'expérimentation, qui a permis de révéler toute la richesse et la diversité génétique des populations naturelles de truite commune. A travers de nombreux articles et communications, ce travail a été largement communiqué à la communauté scientifique nationale et internationale (voir la bibliog raphie en fin d'article). Ainsi, la truite corse, dont l'originalité génétique avait été confirmée par les études de génétique biochimique, a-t-elle connu les honneurs de l'Académie des Sciences (KRIEG et GUYOMARD, 1983).

Le CSP a jugé souhaitable qu'un bilan de l'ensemble de ces travaux, présentant à la fois leurs bases théoriques, les résultats obtenus et leurs conséquences pour la gestion, soit réalisé. C'est le but de ce numéro spécial que nous vous proposons de découvrir.

\section{BIBLIOGRAPHIE}

BARBAT-LETERRIER A., GUYOMARD R. and KRIEG F., 1989. Natural introgression between introduced domesticated strains and mediterranean native populations of brown trout (Salmo trutta L.). Aquat. Living Res., (sous presse). 
BERGOT P., CHEVASSUS B., BLANC J.M., 1976. Déterminisme génétique du nombre de caeca pyloriques chez la truite fario (Salmo trutta L.) et la truite arc-en-ciel (Salmo gairdneri R.). 1 - Distribution du caractère et variabilité phénotypique intra et interfamilles. Ann. Hydrobiol., 7, 105-114

BLANC J.M., CHEVASSUS B., BERGOT P., 1979. Déterminisme génétique du nombre de caeca pyloriques chez la truite fario (Salmo trutta L.) et la truite arc-en-ciel (Salmo gairdneri R.). III - Effet du génotype et de la taille des œufs sur la réalisation du caractère chez la truite fario. Ann. Génét. Sél. Anim., 11, 93-103.

BLANC J.M., TOULORGE J.F., 1981. Variabilité génétique de la performance de nage chez l'alevin de truite fario (Salmo trutta). Ann. Génét. Sél. Anim., 13, 165-176.

BLANC J.M., POISSON H., VIBERT R., 1982. Variabilité génétique de la ponctuation noire sur la truitelle fario (Salmo trutta L.). Ann. Génét. Sél. Anim., 14, 225-236.

CHEVASSUS B., BLANC J.M., BERGOT P., 1979. Déterminisme génétique du nombre de caeca pyloriques chez la truite fario (Salmo trutta L.) et la truite arc-en-ciel (Salmo gairdneri R.). II - Effet du génotype, du milieu d'élevage et de l'alimentation sur la réalisation du caractère chez la truite arc-en-ciel. Ann. Génét. Sél. Anim., 11, 79-92.

GUYOMARD R., 1978. Génétique biochimique et gestion des populations naturelles. Bull. Sci. Tech. Dépt. Hydrobiol., INRA n' 5.

GUYOMARD R., 1986. Gene segregation in gynogenetic brown trout (Salmo trutta L.) : systematically high frequencies of post-reduction. Génét. Sél. Evol., 18, 385-392.

GUYOMARD R., 1988. Diversité génétique et gestion des populations naturelles de truite commune. In J.L. BAGLINIËRE et G. MAISSE (eds), Biologie et écologie de la truite commune, colloque du Paraclet (sous presse).

GUYOMARD R., GREVISSE C., OURY F.X., DAVAINE P., 1984. Évolution de la variabilité génétique inter et intrapopulation de populations de salmonidés issues de même pools géniques. Can. J. Fish. Aquat. Sci., 41, 1.024-1.029.

GUYOMARD R., KRIEG F., 1983. Electrophoretic variations in six populations of brown trout (Salmo trutta L.). Can J. of Genet. Cytol., 25, 403-413.

GUYOMARD R., KRIEG F., 1986. Mise en évidence d'un flux génique entre populations naturelles de truite fario et souche de repeuplement dans deux rivières de Corse. Bull. Fr. Pêche Piscic., 303, 134-140.

KRIEG F., GUYOMARD R., 1983. Caractérisation biochimique d'une sous-espèce particulière de truite fario en Corse. Bull. Sci. Tech. Dépt. Hydrobiol., INRA, nº 13.

KRIEG F., GUYOMARD R., 1983. Mise en évidence électrophorétique d'une forte différenciation génétique entre populations de truite fario de Corse. C.R. Acad. Sc. Paris, 296, 1.089-1.094.

KRIEG F., GUYOMARD R., 1985. Population genetics of french brown trout (Salmo trutta L.) : large geographical differentiation of wild populations and high similarity of domesticated stocks. Génét. Sél. Evol., 17 (2), 225-242.

KRIEG F., GUYOMARD R., MAISSE G., CHEVASSUS B., 1989. Influence du substrat et du génotype sur la croissance et la survie au cours de la résorption vitelline chez la truite commune (Salmo trutta L.). Bull. Fr. Pêche et Piscic., 311, 126-133.

MAISSE G., PORCHER J.P., NITHOUARN A., CHEVASSUS B., 1983. Comparaison des performances en pisciculture d'un hybride intra-spécifique (mâle sauvage $x$ femelle domestique) et de la souche domestique chez la truite commune (Salmo trutta L.). Essai préliminaire d'implantation en ruisseau. Bull. Fr. Pêche et Piscic., 291, 167-181. 